\title{
Non-tuberculous mycobacteria isolated from slaughter pigs in Mubende district, Uganda
}

\author{
Adrian Muwonge ${ }^{1 *}$, Clovice Kankya ${ }^{1,2}$, Tone B Johansen ${ }^{3}$, Berit Djønne ${ }^{3}$, Jacques Godfroid ${ }^{4}$, Demelash Biffa ${ }^{5}$, \\ Vigdis Edvardsen ${ }^{3}$ and Eystein Skjerve ${ }^{1}$
}

\begin{abstract}
Background: The importance of infections caused by non-tuberculous mycobacteria (NTM) in animals and humans has gained considerable recognition during the past few years. In the developed world, where pig production is extensively practiced, studies on mycobacterial infections and related control strategies have received increasing attention. The infections are reported to be caused by a wide spectrum of NTM. Unfortunately, these infections have been less recognized in sub-Saharan Africa owing to lack of awareness and systematic studies. In this study we aimed at isolating and identifying species of mycobacteria involved in causing infections in slaughter pigs in Mubende district of Uganda. Furthermore we wanted to identify factors associated with infection prevalence in the study area.
\end{abstract}

Methods: A total of 363 lymph nodes were collected and cultured for the presence of mycobacteria. Isolates were identified by $16 \mathrm{~S}$ rDNA gene sequencing. A questionnaire survey was administered to identify production related factors associated with infection prevalence. Data were assembled and analysed using descriptive statistics and mixed effects logistic regression analysis.

Results: Mycobacteria were detected in 39 \% (143/363) of the examined lymph nodes, 63 \% (59/93) of lymph nodes with gross lesions typical of mycobacteriosis and 31\% (84/270) of lymph nodes with no visible lesions. Nineteen per cent of the isolated mycobacteria were identified as Mycobacterium (M) avium, of these $78 \%$ and 22\% were M. avium sub sp. Hominissuis and avium respectively. Other mycobacterial species included M. senuense (16\%), $M$. terrae (7\%) and $M$. asiaticum (6\%). This study found free range systems $(O R=3.0 ; P=0.034)$ and use of water from valley dams $(\mathrm{OR}=2.0 ; \mathrm{P}=0.049)$ as factors associated with high prevalence of mycobacteria in slaughter pigs.

Conclusions: This study demonstrated a high prevalence of NTM infections among slaughter pigs in Mubende district of Uganda. M. avium was the most prevalent of all NTM isolated and identified. Free range system of pig management and valley dam water were the most significant factors associated with NTM prevalence in Mubende district. These findings could be of a major public health concern given that it is in a predominantly pork consuming population with 18\% HIV/AIDS prevalence. Therefore, stringent post-mortem inspection at the slaughter houses is of paramount importance to reduce human exposure.

\section{Background}

Non-tuberculous mycobacteria (NTM) are the most prevalent type of mycobacteria. Unlike members of the Mycobacterium tuberculosis complex (MTC) that are highly pathogenic, the majority of NTM have been regarded as non-pathogenic. This opinion is now changing as more NTM have been associated with several human

\footnotetext{
*Correspondence: adrian.muwonge@nvh.no; edroxuk@yahoo.co.uk ${ }^{1}$ Centre for Epidemiology and Biostatistics, Norwegian School of Veterinary Science, P.O. Box 8146 Dep, 0033, Oslo, Norway

Full list of author information is available at the end of the article
}

diseases [1]. NTM naturally occur in the environment, especially water and soil, thus considered to be ubiquitous microorganisms [2]. The absence of documented hostto-host transmission has led to the belief that environment is the primary source of NTM infections for animals as well as humans. Currently, it is estimated that $50 \%$ of the AIDS patients are likely to develop infections due to $\mathrm{Myco}$ bacterium Avium Complex (MAC) predominately $M$. avium, if and when severely immunocompromised [3]. Other NTM reported to cause disease include; M. simiae which is associated with lung disease in immune

\section{Biomed Central}


compromised patients and $M$. terrae isolated from patients with urinary tract infections and chronic tenosynovitis [4]. Reports documenting prevalence are predominantly from developed countries [5-7]. In the Netherlands and Croatia for example, $M$. avium and $M$. avium subsp. hominissuis accounted for up to $39.8 \%$ and $93 \%$ of mycobacteria isolated from porcine lymph nodes respectively [8,9]. There are few studies documenting the prevalence of NTM in developing countries especially in sub-Saharan Africa, however, available reports indicate that the problem could be more comprehensive than previously documented [10-12].

Pig mycobacterial infections are characterized by chronic inflammatory reactions in various body parts, but mostly in the digestive system. Calcified tubercles, inflamed lymph nodes and sarcoid-like granulomas are the most common feature of this disease $[5,10,13]$. The infection usually has a benign course and diagnosis is usually only possible during post-mortem examinations at slaughter $[6,10]$. Studies in Switzerland and Nigeria showed that NTM can be isolated from lymph nodes which appear healthy [13,14]. Although these reports seem to suggest that a considerable amount of mycobacteria could be missed at inspection, stringent meat inspection practice is still the key to reducing the human exposure. Given the lack of appropriate meat inspection practices in majority of sub-Saharan African countries, human exposure to NTM through meat seems to be a viable route. Studies have shown a genetic relatedness between $M$. avium isolates from humans and pigs, adding to speculations that pigs may be a vehicle for NTM infection in humans $[9,13,15,16]$. Production systems are known to play a key role in the distribution of NTM [13]. In Nigeria, it is reported that pigs are mainly infected by ingestion of soil, litter, dust contaminated by faeces of tuberculous chicken or consumption of improperly processed infected chicken [13]. On the other hand reports from Czech Republic and Lithuania indicated that outbreaks in herds have been due to contaminated peat, compost and saw dust $[17,18]$. Therefore, identification of mycobacterial species involved in pig mycobacteriosis is important for prevention and control strategies.

Molecular sequencing using $16 \mathrm{~S}$ rDNA has particularly been used in identification of bacteria with unusual phenotypic profiles and slow growing rates. Not only has it provided insight in aetiologies of diseases but also led to identification of novel mycobacterial species [19]. In Uganda, studies have shown a steady increase in pork consumption, especially in urban areas. Most of the pigs consumed trace their origin back to rural areas $[20,21]$ such as Mubende. Pigs are mostly kept on free range and considered low-input livestock which grow to market size on minimal feed inputs [21]. In Mubende, a high prevalence of HIV/AIDS (18\%) combined with malnutrition has resulted in a high proportion of immune compromised individuals in the population [20]. Recent reports also show an increase in NTM infections in HIV/AIDS patients $[22,23]$, and the large population of free ranging pigs in a predominantly pork eating population has added to speculations that pigs could play a role in the dissemination of NTM in human populations $[13,15]$. There is a need to identify the types of mycobacteria prevalent among the slaughtered pig. Therefore, the aim of this study was to isolate and identify mycobacterial species prevalent among slaughtered pigs in Mubende district. Furthermore, to identify production related factors associated with high prevalence of NTM in the pig population in the area.

\section{Results}

Out of 363 collected and cultured lymph nodes, 93 (26\%) had grossly visible pathological lesion suggestive of mycobacteriosis, while 270 (74\%) showed no visible lesions. Important pathologic characteristics of the lesions included caseous and non caseous granulomatous lesions, inflamed lymph nodes, a sarcoid-like granuloma and cyst like lesions.

Mycobacteria were detected in 143 (39.3\%) of the samples, both in lymph nodes showing macroscopic lesions (63.4\%) and in lymph nodes without visible lesions (31.4\%). The proportion of samples containing mycobacteria varied significantly between the studied sub-counties, a high (58\%) and low (20\%) prevalence were recorded in Kiyuni and Kiganda respectively (Table 1 ). There was no salient difference in prevalence of NTM between pigs slaughtered in open and closed slaughtered houses (Table 1).

\begin{tabular}{|c|c|c|}
\hline Origin of sample & $\begin{array}{l}\text { No of } \\
\text { samples }\end{array}$ & $\begin{array}{c}\text { No / \% of samples containing } \\
\text { mycobacteria }\end{array}$ \\
\hline $\begin{array}{l}\text { Lymph nodes } \\
\text { with lesion }\end{array}$ & 93 & $59 / 63.4 \%$ \\
\hline $\begin{array}{l}\text { Lymph nodes } \\
\text { without lesions }\end{array}$ & 270 & $84 / 31 \%$ \\
\hline $\begin{array}{l}\text { Open } \\
\text { slaughterhouse }\end{array}$ & 223 & 87 / 39.0\% \\
\hline Closed slaughterhouse & 140 & $56 / 40 \%$ \\
\hline Madudu & 113 & $62 / 54.8 \%$ \\
\hline Kiyuni & 35 & $20 / 58.8 \%$ \\
\hline Kiganda & 10 & $2 / 20.0 \%$ \\
\hline Town council & 69 & $19 / 27.5 \%$ \\
\hline Kassanda & 11 & $5 / 45.5 \%$ \\
\hline Kasambya & 16 & $4 / 25.0 \%$ \\
\hline Bagezza & 18 & $6 / 33.3 \%$ \\
\hline Myanzi & 20 & $4 / 20.0 \%$ \\
\hline Butologo & 28 & $11 / 39.3 \%$ \\
\hline Bukuya & 43 & $10 / 23.3 \%$ \\
\hline Total & 363 & 143 / 38.8\% \\
\hline
\end{tabular}


M. avium was the most predominant mycobacterial species identified, accounting for 19\% (27/143) of the isolates. Further analysis revealed that $78 \%(21 / 27)$ of $M$. avium were $M$. avium subsp. hominissuis and $22 \%(6 / 27)$ were $M$. avium subsp. Avium (Table 2). M. senuense, M. terrae and M. asiaticum accounted for $16 \%, 7 \%$, and $6 \%$ of the total number of mycobacterial isolates, respectively (Figure 1). In addition, other species including $M$. simiae, $M$. chelonae and $M$. gordonae were found. Fourteen per cent (20/143) could not be identified because they did not have a match with any reference strain identification in the National Centre for Biotechnology Information (NCBI) database. Associations between variables recorded in the questionnaire and prevalence of NTM in the pigs are shown in Table 3. More mycobacteria were isolated from lymph node samples with grossly visible macroscopic lesions compared to those with no visible lesions $(\mathrm{OR}=3.0 ; \mathrm{P}$ $<0.001)$. Pigs whose source of drinking water was valley dams or water holes harboured more mycobacteria than those getting water from boreholes $(\mathrm{OR}=3.0, \mathrm{P}=0.014$; $\mathrm{OR}=2,0, \mathrm{P}=0.049$, respectively). There was a significantly higher prevalence of free rang pigs harbouring mycobacteria compared to pigs housed in-doors $(\mathrm{OR}=3.0$; $\mathrm{P}=0.034)$. On the other hand, pigs that were reared in predominantly rocky/sandy areas were more likely to harbour mycobacteria compared to pigs reared in loam and clay soil areas. The mixed-effect logistic model also showed a significant variation in mycobacteria isolated between the studied sub-counties than within sub-counties (Table 3).

\section{Discussion}

This study found that mycobacteria were present in $39 \%$ of cultured lymph nodes from slaughtered pigs in Mubende district of Uganda. Sixty three per cent were from lymph nodes with macroscopic lesions compatible with mycobacteriosis and $31.4 \%$ were from those without lesions. This was higher than the $21 \%$ and $14 \%$ isolated from lymph nodes of slaughtered pigs in Nigeria and Switzerland, respectively $[13,14]$. This difference could be attributed to pig management practices. Pigs in industrialised countries like Switzerland and Lithuania are mainly kept indoors, and the exposure rate will therefore probably be lower and in cases where it occurs it is reported to be due to mycobacteria in water, peat and animal bedding [18]. Unlike the pigs in Nigeria, majority

Table 2 Shows M.avium characterisation to Sub-species' level using IS 1245 and IS 901 PCR

\begin{tabular}{lccccc}
\hline Label & M.avium ACCU-PROBE & PCRIS 1245 & PCRIS 901 & ID & \% \\
\hline+ & 27 & 27 & 6 & Maa & 22 \\
- & 116 & 0 & 21 & Mah & 78 \\
Total & 143 & 27 & 27 & - & 19 \\
\hline
\end{tabular}

Maa is Mycobacterium avium sub species avium and Mah is Mycobacterium avium sub species hominissuis. of pigs in Mubende district were reared using free or semi free range management systems. The role of management system in NTM prevalence was further consolidated by the evidence from the regression analysis of data which showed a significantly higher level of mycobacteria in free range or tethered pigs compared to housed pigs $(\mathrm{OR}=3 ; \mathrm{P}=0.034)$. Free ranging pigs have a higher risk of exposure to environmental mycobacteria owing to their food scavenging behaviour. They are not provided with supplementary feeds and as a result are often malnourished and infected by different microorganisms, parasites, and possibly predisposing them to mycobacterial infections. This is in accordance with findings from other studies [1,23,24].

This study revealed that pigs from homesteads with valley dams or water holes as sources of water harboured significantly more mycobacteria than those with boreholes as water sources $(\mathrm{OR}=2.0 ; 3.0$ and $\mathrm{P}=0.049$; 0.014 ) as shown in Table 3. In a previous study carried out in the same environments, more mycobacteria from these open water sources were detected than from boreholes [23]. Given that valley dam water is harvested as storm water from the hilly terrains, it is therefore expected to be highly loaded with microbes including mycobacteria [1,2]. Such water is often shared by humans, livestock and wildlife, and thus constitutes a primary source of numerous infections including NTM.

Previous studies $[5,10,13,14]$ have shown that $M$. avium is the most commonly detected Mycobacterium in lymph nodes of pigs. This is in agreement with the findings of the present study, where M. avium accounted for $19 \%$ of the isolated species. It is however lower than the $39.8 \%$ M. avium isolated from porcine lymph nodes in the Netherlands [8]. M. avium subsp. hominisuis were more prevalent than $M$. avium subsp. avium in this study, which is in agreement with previous studies [9]. In this study, $M$. avium subsp. avium was isolated from $4.3 \%(4 / 93)$ of the lymph nodes with lesions, and $2.1 \%$ from lymph nodes without macroscopic lesions, consolidating the findings from recent studies [18]. Although this is the first documentation of M. avium subsp. avium and M. avium subsp. hominisuis in pigs from Uganda, the former is known to be pathogen for birds and its presence in pigs is reported to indicate contact with infected birds [25]. This indeed could be the case given the free range and tethering system used for rearing pigs in Mubende district. Stringent post mortem inspection remains a critical control method in reducing the exposure risk to human populations. Given the HIV/AIDS status of Uganda, and the fact that $50 \%$ of the AIDS patients are likely to develop infections due to $M$. avium if their immune status is low [3], this finding is of public health interest. 


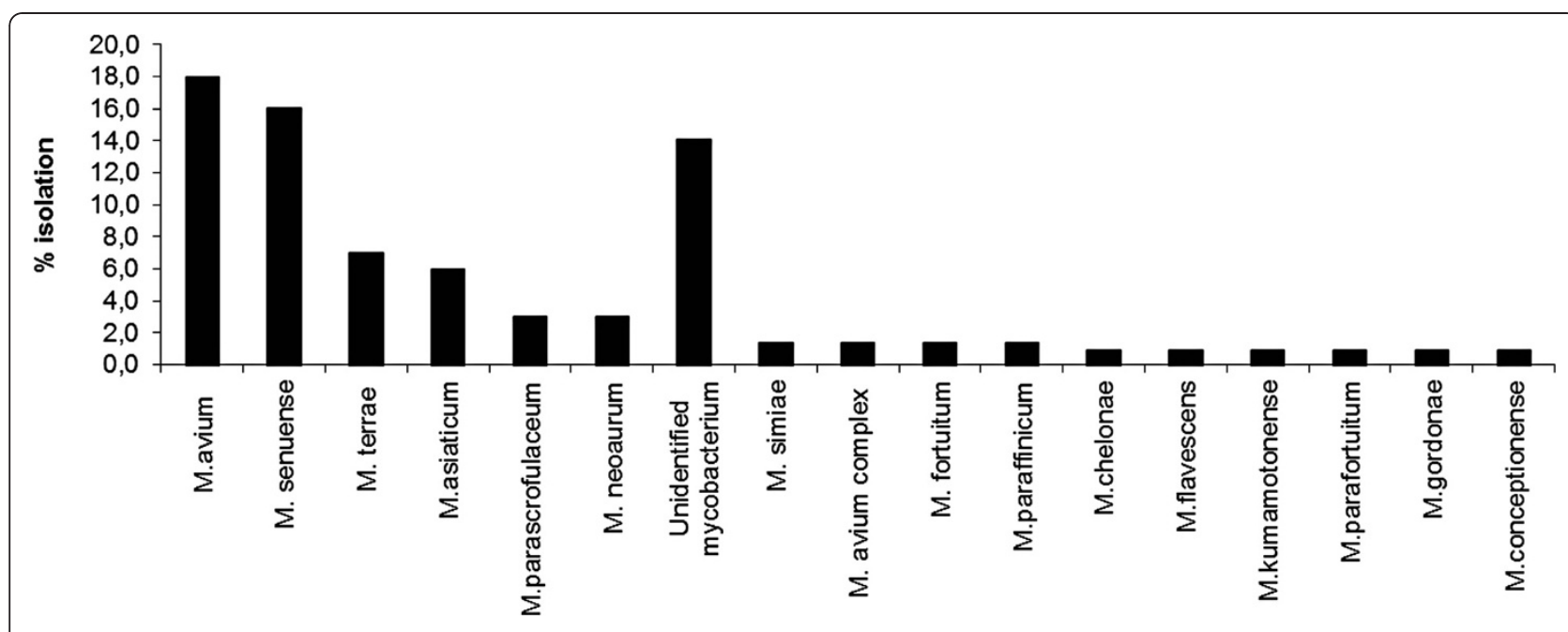

Figure 1 Relative frequency of Mycobacterium spp. isolated from slaughtered pigs in Mubende district, Uganda.

Many different NTM other than M. avium were isolated from the pigs in the present study, most of these species have previously been also isolated from humans and pigs elsewhere $[23,26]$. For instance $M$. simiae has previously been reported to cause pulmonary infection in HIV patients $[4,26,27]$. In Uganda, M. simiae has recently been isolated from the environments inhabited by primates in Mubende district [23], and from febrile patients in Mulago referral hospital in Kampala [27]. $M$. chelonae is known to cause cutaneous infections especially in patients with AIDS $[28,29]$ and $M$. terrae has recently been isolated from the environments in Mubende district [23], suggesting that these free range pigs acquire the infection from the environment. M. terrae has been isolated from patients with urinary tract infections and chronic tenosynovitis [4]. M. senuense has also been isolated from Mubende district before, although its role in disease causation is not well investigated. M. asiaticum was detected from pigs in the present study, but not from the environment in the same study area [23]. Its clinical significance has been well documented in Queensland Australia [30], where it was isolated from patients with extra pulmonary infections. In Queensland, the environment was reported to be the most probable source. M. gordonae, previously isolated from Mubende environments [23], is known to cause infections

Table 3 Mixed effects logistic regression model for factors associated with mycobacteria detected in pigs at slaughter in Mubende District of Uganda

\begin{tabular}{|c|c|c|c|c|c|c|}
\hline Variables & Level & Proportion \% & Odds ratio & P-value & $95 \% \mathrm{Cl}$ & Variance estimate \\
\hline \multirow{2}{*}{$\begin{array}{l}\text { Lymph node } \\
\text { pathology }\end{array}$} & No lesions & 40 & 1 & & & \\
\hline & Lesion & 60 & 3.0 & 0.001 & $(1.55-5.48)$ & \\
\hline \multirow{3}{*}{$\begin{array}{l}\text { Type of water } \\
\text { source }\end{array}$} & Bore holes & 17.6 & 1 & - & - & \\
\hline & Valley dams & 31.3 & 2.0 & 0.049 & $(1.09-5.15)$ & \\
\hline & Water holes & 51.1 & 3.0 & 0.014 & $(1.32-7.31)$ & \\
\hline \multirow{2}{*}{$\begin{array}{l}\text { Pig management } \\
\text { system }\end{array}$} & Housed & 17.7 & 1 & - & - & \\
\hline & Free range & 46.8 & 3.0 & 0.034 & $(1.22-5.97)$ & \\
\hline \multirow{3}{*}{$\begin{array}{l}\text { Soil type in area } \\
\text { of isolation }\end{array}$} & Rocky & 8.5 & 1 & - & - & \\
\hline & Loam & 46.1 & 0.12 & 0.001 & $(0.04-0.39)$ & \\
\hline & Clay & 44.6 & 0.05 & 0.009 & $(0.005-0.52)$ & \\
\hline \multirow{4}{*}{$\begin{array}{l}\text { Month of } \\
\text { sampling }\end{array}$} & September & 18.4 & 1 & - & - & \\
\hline & October & 16.3 & 0.11 & 0.001 & $(0.03-0.33)$ & \\
\hline & November & 14.1 & 0.13 & 0.001 & $(0.04-0.42)$ & \\
\hline & January & 14.2 & 0.3 & 0.008 & $(0.09-0.93)$ & \\
\hline Random effect & Sub county & & - & - & $0.19-2.59)$ & 0.86 \\
\hline
\end{tabular}


especially in patients with an underlying predisposition or immunosuppression such as AIDS, steroids therapy or patients undergoing peritoneal dialysis [4]. Petroleum by-product oxidising mycobacteria, M. paraffinicum [31] was also isolated from pigs.

This study found a higher prevalence of NTM in pigs from Madudu and Kiyuni and lower prevalence in Myanzi, Kiganda and Bukuya. This is could be due to the fact that Madudu and Kiyuni inherently have a high pig population thus apparently increasing the number of pigs exposed to the infection giving higher apparent prevalence of NTM. This is qualified by the large variation $(\mathrm{VE}<=0.86)$ between than with sub counties as shown by the regression model (Table 3).

In rural settings of Uganda, illegal slaughtering of pigs in the backyard and in unhygienic slaughterhouses is a common practice. The lack of strict regulations and enforcement mechanisms in meat inspection practice means that carcasses are usually washed with unhygienic water before being made ready for sale. This water is known to be heavily contaminated, particularly following the rainy season [23]. Therefore, it is possible that some of the mycobacteria isolated might be due to contamination rather than infection. However, their presence on the carcass may pose a health risk for meat consumers.

\section{Conclusions}

This study documented a wide variety of NTMs species occurring at a prevalence as high as (39\%) of cultured lymph nodes from slaughtered pigs in Mubende district, with $63 \%$ and $31 \%$ isolated from lymph nodes with and without gross lesions typical of mycobacteriosis respectively. Given that majority of these were $M$. avium, this could be of public health importance in this predominantly pork consuming population with $18 \%$ HIV/AIDS prevalence. Therefore, implementation of stringent post mortem inspection at the slaughter houses is of paramount importance in order to safeguard the public health.

\section{Methods}

Study district

Mubende is located in the central region of the Ugandan cattle corridor and is divided into two counties; Buwekula and Kassanda. The counties are further sub-divided into 10 sub-counties; Bagezza, Butologo, Kasambya, Kitenga, Kiyuni, Madudu, Bukuya, Kassanda, Kiganda and Myanzi (Figure 2). The district lies at an altitude between 1372$1448 \mathrm{~m}$ above sea level, and pastoral and mixed agrolivestock ecosystems are the predominant modes of livestock production in the different altitude ranges [32]. Mubende is inhabited by approximately 750,000 people, most of whom live in urban and peri-urban areas [32,33]. Sixty-four per cent of the population lives below the poverty line. Pork industry is the most profitable venture in this area, and the district is one of the key sources of pork supply for the growing markets in Kampala, the capital city of Uganda [21,32].

\section{Study design and sampling strategy}

The study design, sampling and sample size determination is described in an earlier study [12], However, in addition to the 93 cultured sub-maxillary lymph nodes with lesions compatible with mycobacterioses described in the previous study [12], 270 sub-maxillary lymph nodes without visible macroscopic lesions were cultured for detection of mycobacteria. The lymph nodes were collected in sterile, labelled sample bottles and transported in an icebox to laboratory at a minimum temperature of $4^{\circ} \mathrm{C}$ for culture of mycobacteria. In addition to lymph node collection, the pigs were traced back to their sources/farms and with consent a questionnaire was administered to the farmers.

\section{Ethical clearance}

Scientific and ethical clearance for this study was obtained from the Uganda National Council for Science and Technology (UNCST). The research ethics committee found this study to be scientifically and ethically in accordance with the requirements and therefore was approved with reference number: HS 879.

\section{Isolation and identification of mycobacteria}

Samples from the lymph nodes were collected and decontaminated, and mycobacteria were isolated as described earlier [12]. Acid fast bacteria, as demonstrated by ZiehlNeelsen (ZN) staining, were identified as Mycobacterium spp, and further identified. Two loop-full of pure colonies from the second or third subculture were killed by heat treatment at $96^{\circ} \mathrm{C}$ for 20 minutes. Genomic DNA was isolated and characterized based on sequencing of the $16 \mathrm{~S}$ rRNA gene using the following primers: 16S8F (AGAGTTTGATCMTGGYTCAG) and 16SM259 (TTTC ACGAACAACGCGACAA) [23]. Isolates found to be $M$. avium were further confirmed by ACCU Probe (GenProbe Inc., San Diego, CA) and IS 1245 PCR. IS901 PCR was used to differentiate between subspecies, as $M$. avium subsp. hominissuis (IS901 negative) and M. avium subsp. avium (IS901 positive) [34,35].

The obtained sequences were edited and analysed in the bioinformatics software Bio-edit (http://www.mbio. ncsu.edu/BioEdit/bioedit.html) and the sequences were blasted at the NCBI Blast database (National Centre for Biotechnology Information). The species identification was strictly determined based on the maximum score and maximum identity values of the reference sequences in NCBI Blast alignment. Isolates with the maximum scores and maximum identities of 100 or $99 \%$ and 


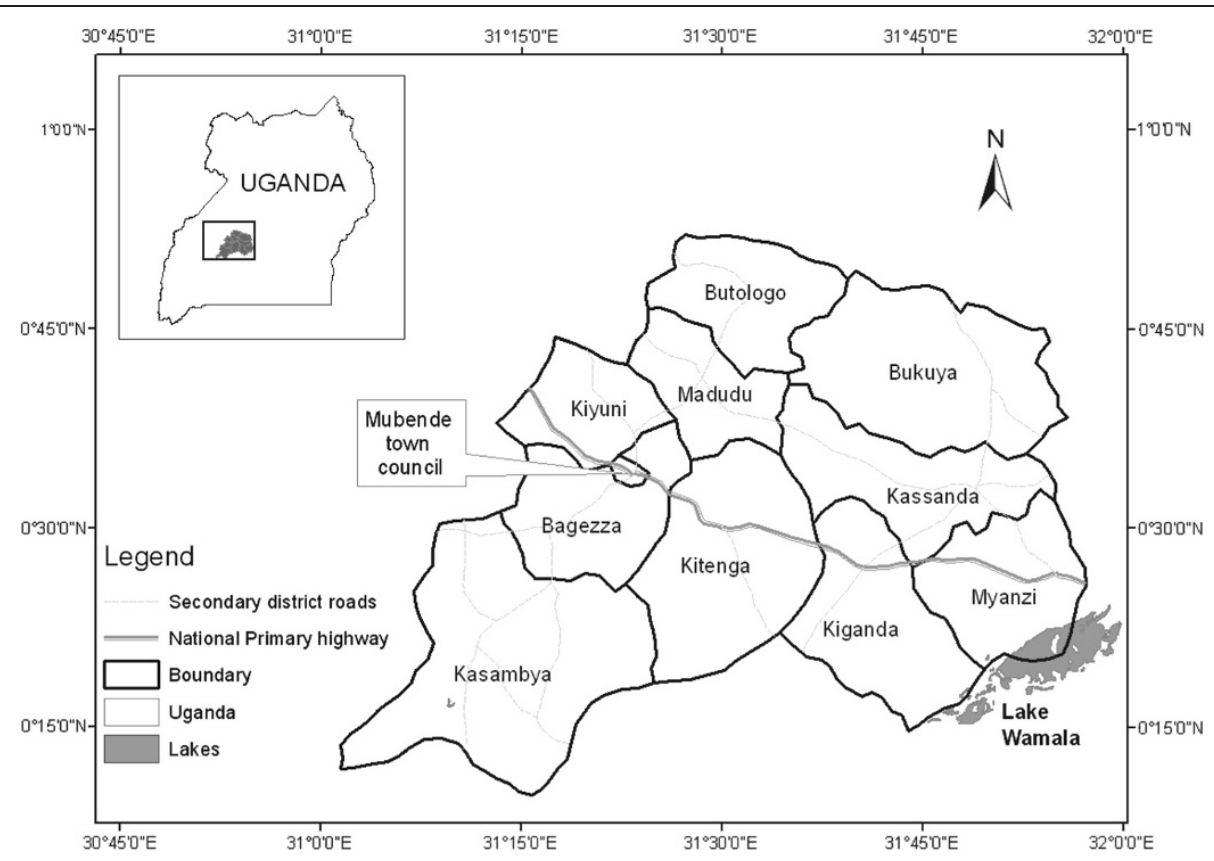

Figure 2 Map of Mubende district in Uganda, with the 10 sub-counties.

documented as approved nomenclature were accepted for species identification [23].

\section{Data collection and analysis}

Information obtained from the questionnaires and the corresponding laboratory results for individual pigs were assembled and validated using Excel $^{\circledR}$ 2007. The data were statistically analysed using Stata (Stata/SE 11 for windows, Stata Corp, College Station, TX). Descriptive and summary analysis was used to estimate the prevalence of NTM infection with respect to presence or absence of acid fast bacteria. A univariable association between presence/absence of mycobacteria in the samples and the recorded individual variables was computed, and only variables that had $(p$ value $\leq 0.25)$ from the univariable analysis were included in the final model. A mixed effect logistic regression model, with Sub County considered as cluster variable, was used to identify variables associated with presence of mycobacteria in slaughtered pigs. Standard methods were used to assess the fit of the final multivariable model.

\section{Competing interests}

This was purely research work and therefore to the best of our knowledge there was no competing interest.

\section{Acknowledgements}

We would like to thank the Norwegian School of Veterinary Science and the Norwegian Veterinary Institute for the financial support. Special thanks go to Mr. Kenneth Okanga, Dr. Allani Assimwe, Dr. Mwanje Francis, Dr. George Luzze, Dr David Walabyeki and Mr. Yawe Willy for the field research. We also thank Vivi Myrann for her excellent technical assistance. Special thanks go to the Mubende district officials and farmers who made this study possible.

\section{Author details}

${ }^{1}$ Centre for Epidemiology and Biostatistics, Norwegian School of Veterinary Science, P.O. Box 8146 Dep, 0033, Oslo, Norway. ${ }^{2}$ Department of Biosecurity, Ecosystems and Public Health (BEP), College Of Veterinary Medicine, Animal Resources \& Biosecurity Makerere University, P.O. Box 7062, Kampala, Uganda. ${ }^{3}$ Norwegian Veterinary Institute, P.O. Box 750, N-0106, Oslo, Norway. ${ }^{4}$ Section for Arctic Veterinary Medicine, Norwegian School of Veterinary Science, Stakkevollveien 9010, Tromsø, Norway. ${ }^{5}$ College of Medicine, University of Arizona, 1656 E. Mabel St, P.O. Box 245221, Tucson, AZ 85724, USA.

\section{Authors' contributions}

AM contributed to the conception, design, and data collection, laboratory work, drafting and writing of the manuscript. CK contributed to laboratory work, data analysis and drafting of the manuscript. TBJ, BD contributed to conception, design, supervision and drafting of the manuscript. VE, DB contributed to the laboratory analysis and drafting of the manuscript. JG and ES contributed to the acquisition of funds, design of study and drafting of the manuscript. All authors have read and approved the final manuscript.

Received: 12 July 2011 Accepted: 7 May 2012

Published: 7 May 2012

\section{References}

1. Falkinham JO III: Surrounded by mycobacteria: Non tuberculous mycobacteria in the human environment. J Appl Microbiol 2009, 107:356-367.

2. Falkinham JO III: Epidemiology of infection by non tuberculous mycobacteria. Clin Microbiol Rev 1996, 9:177-215.

3. AIDSINFONET: Mycobacterium Avium Complex (MAC) Fact sheet 5142011. http://www.aidsinfonet.org/fact_sheets/view/514.

4. Griffith DE, Aksamit T, Brown-Elliott BA, Catanzaro A, Daley C, Gordin F, Holland SM, Horsburgh R, Gwen H, lademarco MI, Olivier K, Michael F, Ruoss S, Fordham VR, Wallace RJ, Winthrop K: An Official ATS/IDSA Statement: Diagnosis, treatment, and prevention of non tuberculous mycobacterial Diseases. Am J Respir Crit Care Med 2007, 4:367-416. 
5. Cvetnić Ž, Špićić Š, Benić M, Katalinić JV, Pate M, Krt B, Ocepek M: Mycobacterial infections of pigs in Croatia. Acta Vet Hung 2007, 1:1-9.

6. Lara GHB, Ribeiro MG, Leite FCQ, Paes AC, Guazzelli A, da Silva Vieira A Barreto Santos AC, Listoni PFJ: Occurrence of Mycobacterium spp. and other pathogens in lymph nodes of slaughtered swine and wild boars (Sus scrofa). Res Vet Sci 2011, 2:185-188.

7. Krizova K, Matlova L, Horvathova A, Moravkova M, Beran V, Boisselet T, Babak V, Slana I, Pavlik I: Mycobacteria in the environment of pig farms in the Czech Republic between 2003 and 2007. Vet Med 2010, 55:55-69.

8. Van Ingen J, Wisselin HJ, Van Solt-Smiths CB, Boeree MJ, Van Soolingen D: Isolation of mycobacteria other than Mycobacterium avium from porcine lymph nodes. Vet Microbiol 2010, 1-2:250-253.

9. Cvetnić ZL, Spicić S, Duvnjak S, Zdelar-Turk M, Benić M, Pate M, Krt B, Ocepek M: High prevalence of Mycobacterium avium subsp. hominissuis in a batch of quarantined pigs in Croatia. Slov Vet Res 2009, 46(4):149-154.

10. Coetzer JAW, Tustin RC: Infectious Diseases of livestock. Oxford University press (New York) 2004, 3:1973-1987.

11. Buijtels PC, van der Sande MA, de Graaff CS, Parkinson S, Verbrugh HA, Petit $\mathrm{PL}$, van Soolingen D: Non tuberculous mycobacteria, Zambia. Emerg Infect Dis 2009, 15:242-249.

12. Muwonge A, Kankya C, Godfroid J, Djonne B, Opuda-Asibo J, Biffa D, Skjerve E: Prevalence and associated risk factors of mycobacterial infections in slaughter pigs from Mubende district in Uganda. Trop Anim Health Prod 2010, 42:905-913.

13. Ofukwo RA, Lortyom BK, Akwuobu CA: Mycobacterium avium and Mycobacterium intracellulare Infections in Slaughtered Pigs in Makurdi, NorthCentral Nigeria: An Emerging Zoonosis. Int J Anim Vet Adv 2010, 2:43-46.

14. Offermann $U$, Bodmer $T$, Audige $L$, Jemmi T: The prevalence of Salmonella, Yersinia and mycobacteria in slaughtered pigs in Switzerland (in German). Schweiz Arch Tierheilkd 1999, 141:509-515.

15. Komijn RE, de Haas PE, Schneider MM, Eger T, Nieuwenhuijs JH, van den Hoek RJ, Bakker D, van Zijd Erveld FG, van Soolingen D: Prevalence of Mycobacterium avium in slaughter pigs in the Netherlands and comparison of IS1245 restriction fragment length polymorphism patterns of porcine and human isolates. Clin Microbiol 1999, 37:1254-1259.

16. Johansen TB, Olsen I, Jensen MR, Dahle UR, Holstad G, Djønne B: New probes used for IS1245 and IS1311 restriction fragment length polymorphism of Mycobacterium avium subsp. avium and Mycobacterium avium subsp. hominissuis isolates of human and animal origin in Norway. BMC Microbiol 2007, 7:14

17. Matlova L, Lenka D, Ayele YW, Bartos M, Amemori T, Pavlik I: Distribution of Mycobacterium avium Complex isolates in tissue samples of pigs fed peat naturally contaminated with mycobacteria as a supplement. J Clin Microbiol 2005, 3:1261-1268.

18. Agdestein A, Johansen TB, Polaček V, Bjørn L, Holstad G, Vidanović D, Kovačević SA, Jørgensen A, Žultauskas J, Nilsen SF, Djønne B: Investigation of an outbreak of mycobacteriosis in pigs. BMC Vet Res 2011, 7:63.

19. Woo PC, Lau SK, Teng JL, Tse H, Yuen KY: Then and now: use of 16S rDNA gene sequencing for bacterial identification and discovery of novel bacteria in clinical microbiology laboratories. Clin Microbiol Inf 2008, 14:908-934.

20. Kisaka A: Mubende Orphans Support Organization, Uganda., . http:// mosouganda.orphanage.org/2009.

21. Waiswa C, Fèvre E, Nsadha Z, Sikasunge CS, Willingham AL: Porcine cysticercosis in Southeast Uganda: Seroprevalence in Kamuli and Kaliro districts. J Parasitol Res 2009, doi:10.1155/2009/375493.

22. Kankya C, Muwonge A, Olet S, Munyeme M, Biffa D, Opuda-Asibo J, Skjerve E, Oloya J: Factors associated with pastoral community knowledge and occurrence of mycobacterial infections in human-animal interface areas of Nakasongola and Mubende districts Uganda. BMC Public Health 2010, 10:471.

23. Kankya C, Muwonge A, Djønne B, Munyeme M, Opuda-Asibo J, Skjerve E, Oloya J, Edvardsen $\mathrm{V}$, Johansen TB: Isolation of non-tuberculous mycobacteria (NTM) from pastoral ecosystems of Uganda: Public Health significance. BMC Publ Health 2011, 11:320.

24. Oloya J, Kazwala R, Lund A, Opuda-Asibo J, Demelash B, Skjerve E, Johansen $T B$, Djonne B: Characterisation of mycobacteria isolated from slaughter cattle in pastoral regions of Uganda. BMC Microbiol 2007, 7:95.

25. Kriz P, Slana I, Mrlik V, Moravkova M, Kralova A, Krizova K, Pavlik I: Mycobacterium avium subsp. avium in domestic pigeons (Columba livia f. domestica) diagnosed by direct conventional multiplex PCR: a case report. Vet Med 2010, 55:87-90.
26. Sampaio JLM, Artiles N, Pereira RMG, Souza JR, Leita JPG: Mycobacterium simiae in patients with aquired immunodeffieciency syndrome. Brzl J Infect Dis 2001, 6:352-355.

27. Ssali FN, Kamya MR, Wabwire-Mangen F, Kasasa S, Joloba M, Donna W, Mugerwa RD, Jerrold J, Johnson JL: A prospective study of community-acquired bloodstream infections among febrile adults admitted to Mulago Hospital in Kampala, Uganda. J Acquir Immun Defic Syndr Hum Retrovirol 1998, 19:484-489.

28. Terry S, Timothy NH, Zurlo JJ, Manders EK: Mycobacterium chelonae: Nonhealing leg ulcers treated successfully with an oral antibiotic. J Am Board Fam Pract 2001, 14:457-461.

29. Kourbeti IS, Maslow MJ: Non tuberculous mycobacterial infections of the lung. Curr Infect Dis Rep 2000, 2:193-200.

30. Grech M, Carter R, Thomson R: Clinical Significance of Mycobacterium asiaticum isolates in Queensland, Australia. Clin Microbiol 2010, 48:162-167.

31. Nadege T, Adekambi T, Toney S, Yakrus M, Butler WR: Revival and emended description of 'Mycobacterium paraffinicum' Davis, Chase and Raymond 1956 as Mycobacterium paraffinicum sp.nov., nom. rev. Int J Sys Evol Microbiol 2010, 60:2307-2313

32. Mugisha OR: Uganda district information handbook, Fountain publishers Kampala Uganda; 2007:19-35.

33. Uganda Bureau of statistics (UBOS): Uganda demographic and Health survey 2001. http://www.ubos.org/onlinefiles/uploads/ubos/pdf\% 20documents/Uganda\%20DHS\%202000-01\%20Final\%20Report.pdf.

34. Johansen TB, Djønne B, Jensen MR, Olsen I: Distribution of IS1311 and IS1245 in Mycobacterium avium subspecies revisited. J Clin Microbio/ 2005, 5:2500-2502.

35. Ahrens P, Giese SB, Klausen J, Inglis NF: Two markers, IS901-IS902 and p40, identified by PCR and by using monoclonal antibodies in Mycobacterium avium strains. J Clin Microbiol 1995, 5:1049-1053.

\section{doi:10.1186/1746-6148-8-52}

Cite this article as: Muwonge et al:: Non-tuberculous mycobacteria

isolated from slaughter pigs in Mubende district, Uganda. BMC Veterinary Research 2012 8:52.

\section{Submit your next manuscript to BioMed Central and take full advantage of:}

- Convenient online submission

- Thorough peer review

- No space constraints or color figure charges

- Immediate publication on acceptance

- Inclusion in PubMed, CAS, Scopus and Google Scholar

- Research which is freely available for redistribution 